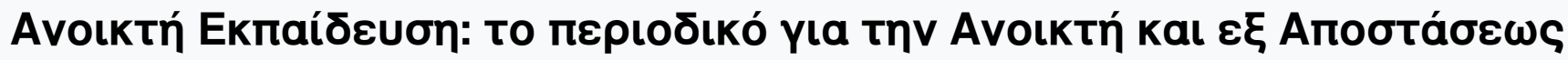

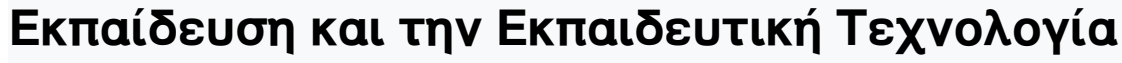

Tón. 15, Ap. 1 (2019)

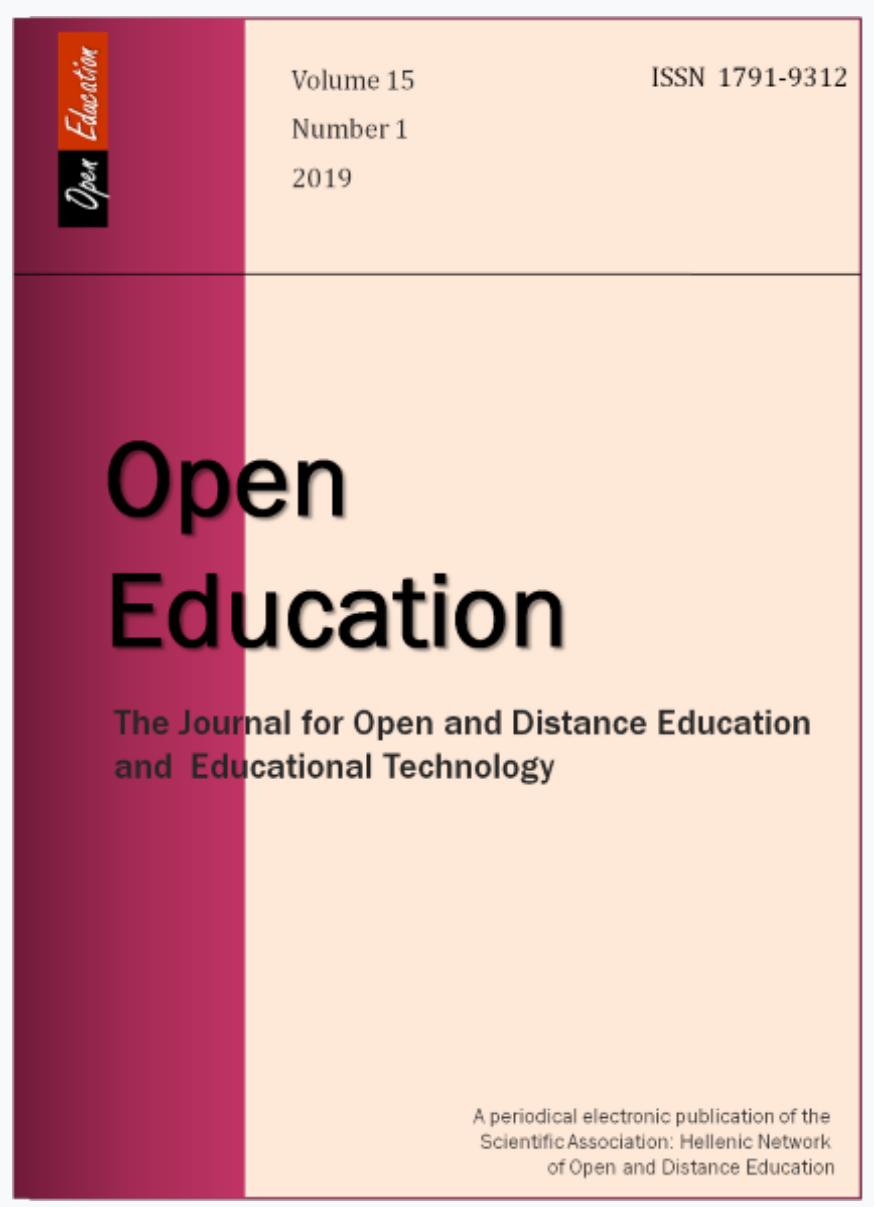

The Hellenic Open University: Innovations and Challenges in Greek Higher Education

Sofia Theodor Papadimitriou, Antonis Lionarakis, Vasiliki loakeimidou

doi: $10.12681 /$ jode.20211

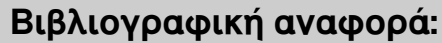




\title{
The Hellenic Open University: Innovations and Challenges in Greek Higher Education
}

\author{
Antonis Lionarakis \\ School of Humanities, Dean \\ Academic and Research Staff \\ Hellenic Open University \\ alionar@eap.gr \\ Sofia Papadimitriou \\ Tutor-Counselor \\ Hellenic Open University \\ Educational Radiotelevision \\ sofipapadi@gmail.com \\ https://orcid.org/0000-0002-7708-106X \\ Vasiliki Ioakimidou \\ $\mathrm{PhD}$, Hellenic Open University \\ silviioakimidou@yahoo.gr \\ https://orcid.org/0000-0003-2262-9806
}

\begin{abstract}
The Hellenic Open University (HOU) is a state university equivalent to all the others in Greece. This article highlights key moments in the 20-year history of the HOU, relevant expertise, lessons learned so far and challenges that threaten or inspire a quality culture of enhancement. Combining the theoretical principles of distance education with empirical research implemented in the HOU, the article illustrates its achievements and the innovations brought to Greek higher education that have had a great impact and affect both undergraduate and post-graduate courses in all Greek universities. The new complex and diverse role of the tutors, the liberation of the educational process from the constraints of time and space, the interaction between tutor-student-institution, the autonomous and independent route of self-directed learning and also the crucial role of the educational material in the learning process are some of the innovations, which define a new educational environment, unknown until recently in Greece. In this context, lifelong learning and adult education policies directly link wider social classes to educational processes. This educational mobilization of a wider social class that until recently was outside the educational process is also the great contribution of the HOU to educational reform in the country. HOU faces new challenges in the $21^{\text {st }}$ century and has to commit to continuous quality enhancement in order to serve adult students' needs.
\end{abstract}

\section{Keywords}

Hellenic Open University, distance education, open education, online learning, quality in education 


\section{Introduction}

The rapid evolution of new technologies and the increasing global competition among universities within the knowledge society change the landscape in higher education (HE). Universities need to evolve a response to challenges like internationalization, mobility, and the social and geographical variety of students (Ioakimidou \& Lionarakis, 2017).

Open universities worldwide use the distance education (DE) methodology and models based upon a scalable approach whereby instruction is delivered to large numbers of students. Even though the traditional universities nowadays provide more and more online courses targeting though to the "best" students, the role of open universities highlights their social agenda widening the access to higher education for all.

Courses and programs delivered at a distance require a unique set of professional competences from the tutors. Tutors in DE have a complicated and different role to those in a traditional educational system. Their professional development is the vehicle for the achievement of quality teaching and learning for their students. Students may follow personalized learning paths and cultivate competences like creativity and critical thinking. What is different is the way open universities understand their students' needs and respond to them.

The paper starts with a brief description of the HOU's character, its role, its special features, and lessons learned so far. A discussion then follows on innovations and achievements in Greek HE and their impact in Greek society. Research findings in the HOU focusing on communication, tutorials, assessment of assignments, as well as student attrition are commented on to highlight the special role of the tutor-counselor in the HOU's DE model (Picture-2). Based on this model the design requirements of its strategic professional development are outlined. Challenges faced by the HOU are presented and finally the article concludes with a detailed discussion on the social role of open universities and suggestions focusing on quality and continuous enhancement.

\section{Methodology}

The article provides a historic overview aiming to present key moments in the history of the HOU but also the challenges it faces and the contribution it makes.

It is a critical approach, analysis and interpretation, based on literature review and also on conclusions and findings in five doctoral and several postgraduate theses in the HOU, papers published in the International Conference of Open and Distance Learning as well as the Open Education journal in Greece. The reason for this choice is mainly the lack of numerous scientific papers on the HOU's route and its contribution to Greek higher education. On the occasion of a SWOT analysis (2006) our review focused on HOU's strengths/innovations, its weaknesses/opportunities for enhancement, threats but mostly challenges.

The critical review comes from:

- The Dean of the School of Humanities, Academic and Research Staff (ARS) and founding member of the initial design and organizational team of the HOU.

- A tutor-counselor/Adjunct Faculty $(A F)$ member of the HOU and a doctoral researcher, both with $\mathrm{PhD}$ theses and long term research in the HOU.

This review of the HOU's 21 years of operation provides a case study highlighting the good practices and challenges of the open university. The reviewers' experience is important as it provides additional background. 
The HOU has faced several changes over the last few years like new programs which means more people engaged in the university, electronic meeting with tutors and students and MOOCs. The guiding research questions in this article raise related issues:

1. What is considered to be the HOU's contribution to the Greek tertiary educational landscape? What innovations has the HOU brought?

2. What challenges does the HOU face currently and how can they be overcome to enhance the quality of courses?

The answers to these questions and the discussion that emerges reflect issues that may concern other open universities. The aim is to highlight issues that are now of main interest in the HOU and other open universities through retrospective snapshots to justify or criticize crucial choices today.

\section{The Hellenic Open University: Foundation and Mission}

The HOU has been established since 1997 as a self-administered state university with its premises located in Patras (HOU, n.d.) and it aims to fill the gap in open HE in Greece. It is the only university in the country that offers exclusively DE degrees in a contemporary, flexible way. The mission of the HOU is to provide high-quality university education via distance learning at both under/postgraduate level. For that purpose, it develops and implements appropriate learning material and methods of teaching. The promotion of scientific research, as well as the development of the relevant technology and methodology in the area of distance learning falls within the scope of its objectives (HOU, n.d.). 

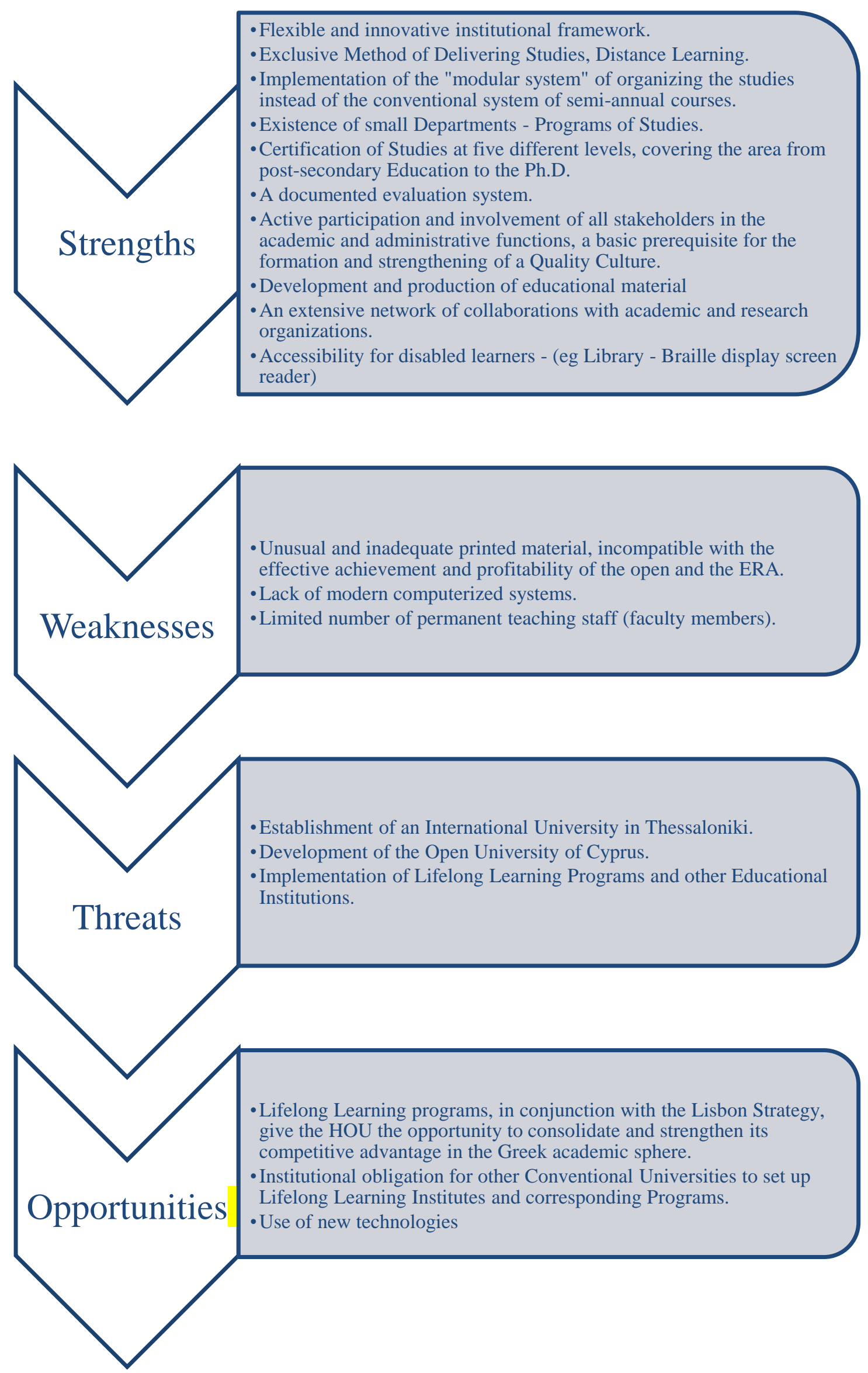

Picture 1: The SWOT analysis at the HOU 
The HOU's foundation was not the result of deep social or political discussions, sufficient planning and preparations. It was rather an urgent response to contemporary changes in the international educational landscape and despite the odds, as is obvious even in the SWOT analysis (2006) it evolved into a growing institution (Koustourakis, 2006).

HOU's success and the high value placed on it in Greek society are evident in the influx of thousands of candidate students. In order to fulfill its mission, the HOU bases itself on the ideal of open quality education, the methodology of distance learning and the horizontal organization of the university.

The HOU offers undergraduate and postgraduate courses through open and distance education using a variety of methods for distance learning. Undergraduate students are allowed to register for a maximum of three modules per academic year while postgraduate students are allowed to register for a maximum of 2 or 3 modules depending on the course, be it a regular registration or registration for examinations.

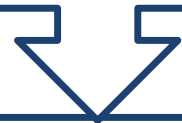

Thirty eight courses are currently offered in the HOU. Students are provided with various learning materials that can be used at home to study: printed material, set books, audio and video material, cdroms/software, specially prepared for distance learning. Students must plan their own time to study, work on course activities, and hand in assignments by the due date. Course material is accompanied by a study guide that provides guidance, the syllabus, and study plan for each course module.

The assignments practice was adopted in each module, as a good practice implemented in the OU UK. There is a strict timeframe for students to deliver assignments, as well as for their correction and evaluation. New courses with six-month plans are designed with a lighter weekly workload and only one assignment by the end of the module.

Courses with annual modules require 4 to 6 written assignments and are evaluated by the tutor. Written assignments are compulsory for all students and must be sent to the tutor by the due date referred to in the study plans. Students are continuously supported by the academic staff and they are contacted regularly. The ratio of tutor / student is approximately one to thirty (1/30). Students participate in 5 or 6 face-to-face meetings during the academic year which are coordinated by the tutor.

Attendance at face-to-face meetings is optional for the learners though it's strongly recommended as students have one more opportunity to solve problems and clear up misunderstandings, to improve their understanding and performance through tutor-student and student-student communication. In the academic year 2017-18 for the first time students had the opportunity to attend/join electronic meetings through teleconferencing.

Picture 2: The distance education methodology in HOU

Overall HOU's operation denotes "a new educational philosophy and methodology" (Koustourakis, 2006:51) as for the first time in Greek HE the emphasis is on:

- the students' needs and the student - tutor communication and relationship;

- the creation and the use of appropriately planned and developed educational material/the Educational Content, Methodology and Technology Unit; 
- the tutors' team approach culture;

- open access to university without exams;

- face-to-face meetings, written assignments that contribute to the final grading after final exams;

- the evaluation system/the Evaluation and Training Unit;

- exclusive use of the methodology of DE;

- new methods for teaching using synchronous and asynchronous e-learning environments and a few optional face-to-face meetings.

Nowadays, the HOU has four Schools (Social Sciences, Applied Arts, Science and Technology and Humanities). Currently, over 30.000 undergraduate and postgraduate students are registered. They are educated by an academic faculty of around 50 members (ARS), supported by 2000 adjunct lecturers (AF), professors, post-doctoral researchers, laboratory support staff, instructors, as well as around 200 administrative support staff (HOU, n.d.).

The HOU follows an autonomous, innovative route in the Greek tertiary reality (Koustourakis, 2006), though there are challenges, as well as opportunities to enhance its quality.

\section{Innovations and Achievements in Greek Higher Education}

The organization of studies in the HOU is presented in brief in picture 2, though learning material designed and developed following the principles of $\mathrm{DE}$, the new role for tutors and the university's dedication to the pursuit of quality are some of the HOU's most innovative characteristics.

The following are innovations introduced since the HOU's founding (HOU, n.d.):

- Study based exclusively on distance learning methodology (Picture-2).

- The application of a modular system and the replacement of traditional courses with a more flexible form of modular courses.

- The establishment of an Educational Material and Methodology Research laboratory.

- The founding of an Evaluation Unit.

Further changes have been introduced in the university during the last few years:

- The HOU accepts all students willing to study.

- New programmes were introduced offering mainly postgraduate degrees but also certificates of attendance on one or two modules or short programmes.

- The university offers optional exclusively e-learning programmes.

HOU's students are the most critical reviewers of its programs. The university is tested as the competition becomes more intense every day. Innovations and its quality will determine its route.

Since its foundation the HOU has established Independent Units in order to support its needs. Today there are seven Units:

1. The Evaluation and Training Unit (ETU)

2. The Quality Assurance Unit (QAU)

3. The Educational Content, Methodology and Technology Lab (e-CoMeT-Lab)

4. The Psychological Counseling and Student Support Service

5. The Employment \& Career Structure

6. The Career Office

7. The Entrepreneurship and Innovation Unit 
The ETU and the e-CoMeT-Lab were established at the HOU's foundation, at a time when nothing like that existed in Greek universities, and that's the reason why it is more than worthwhile to mention them.

\section{The educational material as a catalyst in distance learning}

Even a brief, non-systematic review of the literature as well as of three $\mathrm{PhD}$ theses in the HOU (Hartofylaka, 2012; Manousou, 2008; Siakas, 2011) is sufficient to understand the importance and the complexity of the teaching material in DE. The traditional scheme, where the learner learns through the processing of the information transmitted to him by the instructor, is transformed adding a crucial factor: the teaching material especially created to serve DE needs.

Today, in the majority of open universities, distance learning material or the "training package" (Rowntree, 1994) is, regardless of its form, a "pre-fabricated and stored teaching" (Holmberg, 1995) and at the same time a central factor that as a dynamic tool defines the quality of the learning experience and its results (Hartofylaka, 2007). Since its beginning the HOU has produced the vast majority of the educational material needed in modules following the principles of $\mathrm{DE}$ even though some modules chose to use material borrowed from other open universities (Hartofylaka, 2012) or books available in bookshops developing appropriate guides to support them. The HOU formed groups to plan, write, edit, check and enhance the educational material. These groups consisted of the Coordinator of the module, the writers, the critical reviewers, the expert on DE methodology, and the linguistic editor (Hartofylaka, 2012).

The Educational Content, Methodology and Technology Laboratory (e-CoMeT-Lab) operates as an independent unit in the HOU. The e-CoMeT-Lab supports HOU in applying educational, methodological and technological innovation in distance learning and educational content development including programs in digital and interactive environments.

Based on the importance of the educational material in relation to the quality of the education provided, the e-CoMeT-Lab coordinates the process of developing digital educational content by providing full technical support and training to developers and by featuring modern equipment and software. In this context, the Lab has written pedagogical specifications according to the principles of distance learning as well as up-to-date scientific and technical specifications appropriate to each kind of digital educational material.

The Lab has built a distinctive profile in research for DE through its expertise in developing high quality educational material in compliance with international standards.

\section{Evaluation and Professional Development}

The Evaluation and Training Unit (ETU) has operated since 1997 aiming at the enhancement of HOU's services. Moreover, this Unit aims to support the assessment procedures in order to depict the quality of:

- tutors' educational work,

- the educational material and methods

- the administrative services.

In the context of internal evaluation the ETU carries out assessments of:

- the tutors and the educational processes by students;

- the tutors by Coordinators;

- the Coordinators and the Course Directors; 
- the educational material by the tutors.

- In order to achieve these goals the Unit:

- creates and analyses statistics - comparative data;

- runs the assessment procedures using qualitative and quantitative approaches.

The evaluation is conducted electronically using questionnaires and reviews especially developed for this purpose. The Unit informs people in key positions in the university about the assessments' results and cooperates with other Units.

The ETU, the QAU and the Hellenic Quality Assurance and Accreditation Agency $(H Q A)$, the independent body responsible for quality assurance in tertiary education in Greece, act complementarily in order to contact internal and external evaluations.

Furthermore, the ETU is responsible for running a quality management system based on the International Standard on Quality Management EN ISO 9001:2008. Finally, the Unit provides data to, and the HOU shows up in university rankings such as: Webometrics, U-Multirank and Schimagoir.

Moreover, the ETU is in part responsible for the tutors' professional development. Training seminars mainly for new AF were launched during the academic year 201213. However, a training strategy for all academic staff has not yet been developed, despite the increased demands and differentiations in their role, origin and often parallel work in traditional universities.

Courses and programs being delivered at distance require a unique set of professional competences. Important parameters of the DE methodology make evident the multiple and complex role of the tutor. Multiple dimensions of the role include teaching, counseling, management and facilitating (CoL, 2003). The instructional-academic role concerns (Papadimitriou, 2014):

- Support and guidance for students to understand content, develop and implement effective learning processes;

- Find motivating strategies that will allow the development of all students' competences to the maximum extent.

The complexity of the tutors' role is due to (Papadimitriou, 2014):

- Turning from the traditional role to a new one.

- The ambiguity of the new role.

- The dual contradictory processes of support-counseling and assessment of the student.

- The specific characteristics and different backgrounds of adult students.

- The importance of the second educational opportunity offered to students.

The elements that differentiate the role of the tutor in DE from traditional education according to research in the HOU are the following (Papadimitriou, 2014):

- Distance communication requires special skills.

- Creation of appropriate educational and digital educational material based on the principles of DE.

- Organization and discipline over time, following the study schedules of the students.

Tutors in the HOU shaped a totally different role, and are expected to be agents of quality.

Almost all of the tutors in the HOU consider the role of counseling, support, empowerment and encouragement of students to be of prime importance (Papadimitriou, 2014). Assessment and teaching are important elements of their role, 
with particular reference to "helping them to learn how to learn", i.e. cultivating metacognitive skills to improve their work.

Open universities promote teachers' professional development in various ways using mentors, seminars, workshops and teachers' mobility abroad. The great demand for teachers in the HOU has created a group of scientists and academics who have no experience in distance learning and administrative issues in open universities but have experience in their field of science in traditional education. Training is necessary because (Lionarakis, 2012):

1. The HOU follows a learning methodology different from traditional universities and requires differentiated practices. It develops its own educational material, which is especially designed for independent study. The role of the tutor focuses primarily on supporting this material.

2. Students, regardless of age and experience, are invited to study in a demanding environment. Their support is multidimensional because it covers the full range of activities and needs.

3. Tutors should activate students, solve questions and create an environment of interaction and collaboration.

4. Assignments are learning tools in the students' hands. Tutors ask for students' creative engagement, in order to enable them to discover ways to learn.

5. The tutor maintains the teaching role while at the same time he/she supports and he/she encourages his/her students. The interpretation of these dimensions depends on each tutor's personality and experience.

Paying attention to both students' and teachers' responses, the most popular common request is for professional development on issues related to open and DE (Papadimitriou, 2014). A survey conducted in the HOU from 2009 to 2013 (Papadimitriou, 2014) reflects the current situation of both new and experienced AF and explores the expectations of the training process and their proposals for professional development. A supporting environment was designed, developed and evaluated, which enriches and supports the work of AF, combining the methodology of DE, adult education and collaborative learning environments to the cognitive subject. The preliminary results recorded a positive impact to students' experience.

\section{Challenges faced by the HOU Quality education for all}

Mass education leads to the question of quality. Over the last few decades there has been a significant increase in publications on the issue of quality in HE (Steinhardt et al, 2017) and that demands that the universities refresh their strategies for development (Shah \& Nair, 2014:149). Planning for the future the universities strive to meet the expectations and the needs of various stakeholders so as to (Woodhouse, 1998: 270):

- be appropriate for all those people and functions that education must serve;

- take advantage of the best that distance and electronic modes can offer;

- retain the best of what the pre-electronic experience has taught.

The HOU (n.d.) recognizes that quality is about dedication to basic values like:

- the satisfaction of various stakeholders' needs;

- technical, and scientific excellence and innovation;

- the social responsibility of its work and results.

A system of open education in relation to DE, that involves qualitative dimensions, may offer "educational democracy in action" (Panagiotakopoulos \& Lionarakis, 2001:101) and it may become a role model for other institutions in the country. 
Necessary conventions include: the appropriate strategic plan, the diffusion of the desirable quality orientation across every aspect of the institution's operation and well aimed interventions for change and enhancement.

Strong and clear strategies aimed at development and quality offer self-confidence to the staff; to the students and every stakeholder. These show the institution's commitment to everyone involved declaring that all the people in the university together can meet the current challenges (Shah \& Nair, 2014). Besides, the risk for open and DE is much bigger, as they do not address the elite, they do not address only the best, instead they address every person that wants to study, people working, people with families, people that do not come from privileged social groups. That means, as M. Brown explains, that open universities should take the responsibility for dealing with the risk in a clear and decent way (Ioakimidou, 2016b), with respect for and pride in everything they believe in and serve (Tait, 2015).

A university doesn't work beyond the general context. It is affected by, but also affects, the context. So there are conditions or factors that may work in a rather opposite from the desirable way or they may drive to an undesirable direction. And how could this work vice-versa? Small realistic targets, which are constantly assessed and redefined, may be an answer. Innovation, quality as change and continuous enhancement should be the desired orientations.

If quality is seen as a dynamic transformative process that leads an institution to continuous enhancement and development, then assessment or evaluation becomes its dominant metacognitive tool for ensuring continuous changes and improvements (Ioakimidou \& Lionarakis, 2017: 17). The ETU in the HOU is responsible for promoting and cultivating the diffusion of a quality culture. For example, the Unit is in part responsible for the tutors' professional development. It is not by chance that this is recognized in the HOU and the teachers' professional development is closely related to evaluation and quality (Ioakimidou, 2018). Assessments may highlight issues that could become part of the themes or the content of the tutors' training sessions. The ETU should also evaluate the professional development procedures, methodologies and techniques, every aspect that may become more effective. That works at a metacognitive level so it may enhance the whole process. Besides, new trends whose central characteristics are flexibility and openness, like MOOCs or Open Educational Resources (OER), should be included in quality assessment and quality enhancement mechanisms (Ossiannilsson, Williams, Camilleri, \& Brown, 2015).

The HOU, in an attempt to follow international educational trends, developed two MOOCs to support tutors' professional development. The question is whether this is enough to meet and support all tutors' needs. Even though some initial attempts have been made, most of the MOOCs worldwide don't follow the formal evaluation and quality system at a national or even an institutional level (Ossiannilsson et al, 2015). As a consequence there is not data to inform enhancement. In the HOU, a professor, who is the head of the ETU, comments that (Ioakimidou, 2018) there is the provision: a tutor that accredits his/her knowledge gained in the MOOC may assess the whole procedure. What is not clear yet is the use of the assessment data gathered. That's probably an indication that there is not a wider plan on using assessment data systematically in order to enhance processes and services offered.

\section{Providing expertise to traditional Universities}

The HOU, based on its experience, for example in the creation of educational material with specific characteristics or flexible systems to support students, but also on its inherent orientation towards innovation and quality, may offer traditional universities 
its expertise in the production and the advancement of flexible, pioneering mechanisms on educational empowerment (Ioakimidou, 2018). Besides, DE culture and openness greatly affect some dimensions in HE. For example, most postgraduate courses in traditional universities have provided online environments and use methods borrowed from DE.

As a tutor in the HOU, who's also a professor in a traditional university, mentions probably the most important legacy that the HOU offered Greek HE is the central position occupied by the educational material that is created, developed and supported following certain principles and which allows students to engage with it and learn (Ioakimidou, 2018). Another tutor comments that she was amazed when she saw the educational material used in the HOU for the first time, she loved it, she wished she could use something similar in the traditional university where she also teaches and now she participates in a team that prepares new educational material in the HOU (Ioakimidou, 2018).

As a professor, who is head of the ETU, comments (Ioakimidou, 2018) the HOU started using anonymous assessments 20 years ago and nowadays traditional universities ask for the HOU's expertise and experience. Now the HOU is moving ahead to enrich its evaluation system with qualitative data according to what the Head of the ETU explains, so the extent, the volume but also the quality of evaluations is unique in the Greek context (Ioakimidou, 2018). The next challenge is probably the systematic use of the assessment results in order to facilitate improvement- This qualitative turn together with the vast quantity of assessments seems to be a further development that maybe shows that all these rather mature processes of assessment could be an important contribution to a dialogue and exchange of experience with traditional education (Ossiannilsson et al, 1915; Bates, 2007).

\section{New and preparatory programmes}

The HOU started its operation with twenty-nine programmes, a little bit later three more were added. In the year 2016-2017 six more new programmes started, in 20172018 another three were offered and some more are planned to start (Ioakimidou, 2018).

A series of changes are introduced with the new programmes. The most important changes are located at the following points (Ioakimidou, 2018):

- The duration of each module is a semester during which only one assignment is usually prepared, according to the older practice, but it is elaborated on a weekly basis with smaller workloads.

- Students have the option to choose whether to attend face-to-face or online meetings.

- Educational material is exclusively digital.

- Three new courses were founded in collaboration with the Universities of Thessaly and Western Macedonia.

Challenges remain even for the new programmes such as their internationalization, the response to the market demands and interdisciplinarity.

Besides, when barriers and academic requirements arise for students who don't have any similar support background, dropping out becomes an important issue for the university community. Open universities accept students who are likely to have been outside the education system for many years. "Preparatory programs empower students at the undergraduate level in particular" (Hartofylaka, 2012) and ensure their smooth adaptation to the new education system. The development of preparatory programs at the beginning of the curriculum, in addition to meeting the individual 
needs in each field of study, could aim to develop students' skills in new technologies horizontally in order for them to be able to make the maximum use of them, to seek reliable information and communicate with ease.

D. Laurillard (Ioakimidou, 2016a) thinks that since students in an open university have a different profile to students in traditional universities, and face various difficulties that may include academic writing, English or new technologies, then a MOOC may work as a kind of foundation course. It could function as a pivot to open up education to more people and at the same time to increase their chance of gaining a degree.

\section{Discussion and Conclusions Filling the gap in open $\mathrm{HE}$}

Open universities offer opportunities for studies and qualification to adult students using the methodology of DE. The HOU aims to fill the gap in open HE in Greece by offering exclusively DE, an alternative way of organizing studies and new methods for teaching.

In his article entitled "What are open universities for?" A.Tait (2008) opens up a conversation about a common perception on the evolvement of the role of open universities based on ethical and political criteria aiming at development. The open universities are founded under specific social and political circumstances, they are in a dialectical relationship with the context in which they operate, they interact, state opinions and affect each other. They are ahead of evolution; they prepare, deliver, support and defend it.

From its foundation, a university declares its aims, it forms a specific context to offer services and it works on specific administrative, managerial or educational choices influenced by the historical, social, economic, cultural, and political conditions (Lionarakis, 2006:24). This is a political act and political dimensions exist in the curriculum, in the educational material, in the everyday choices a tutor makes in terms of teaching methodology and techniques, assessment processes, the methods, the tools or the criteria used. All these express political choices but also broader social pursuits (Jani, 1986:57). These define and ideally promote the continuous enhancement of quality in education. A fundamental orientation is the formation of an institution that learns through dialogue and experience and adjusts to the wider context (Laurillard, 2002:215). What is required is an agenda with issues to discuss which aims to enhance the critical, creative, and reflective processes that constitute the key points for constructing knowledge (Harvey \& Newton, 2007).

The governments promote their policies, and the transformation of these policies into action, through networks, agencies, organizations, and committees. The educational institutions should filter these, they should join in discussions with all stakeholders, they should criticize when necessary, they should influence, they should intervene in a constructive way and they should offer feedback on social and political issues. The constructive critique of words and practices should be related to what has been said, what the argumentation is, who speaks, how he comes to his conclusions, when he says these things and with what authority (Passias, 2012:47). Open universities should participate in the formation of a wider social policy, if they wish to see their needs and values reflected in the system (Pacey \& Keough, 2003:411).

Open universities may participate in and influence the socio-cultural context instead of just reacting to it (Pacey \& Keough, 2003). This dynamic involvement with organized procedures, actions, and evaluations, redefining the aims that target quality, will form its radical and innovative character. In order to achieve that the open 
universities should always reflect on what a university is in such a way as to challenge, focus on quality and innovate (Tait, 2008:93). It is precisely these focus points (Apostolidou, 2011:48) that differentiate open universities from traditional.

\section{The HOU's contribution}

Regarding the first research question concerning the HOU's contribution to the Greek tertiary educational landscape, the critical literature approach highlights the following: The HOU emerged in the Greek educational landscape as an answer to the social context, the social-economical and technological evolution, as an alternative and innovative perspective. It was the first and remains the only university in Greece offering degrees using the methodology of $\mathrm{DE}$ and also respecting in practice the basic principles of open education using a flexible educational system without time or territorial constraints. So, the HOU has an important mission to serve and fulfill (O’Malley \& McCraw, 1999 as cited in Lionarakis \& Papademetriou, 2003):

- access to HE for a large number of people;

- pioneering work in academic and administrative innovation and quality;

- promotion of open and DE that tends to be the leading actor on the global educational scene.

The last few years have seen an attempt on the part of the HOU to attract a greater number of new students. Respecting openness, every student willing to study is accepted. That doesn't mean that there is nothing else to be done since the tuition fees remain high in a country facing intense economical issues. The more students that start studying in the HOU the bigger the need is for continuous enhancement in every aspect of the university's operation.

$64 \%$ of the AF in the HOU come from conventional tertiary education (Ioakimidou, 2018). While working in traditional universities, they usually teach in the HOU as a secondary job, and sometimes they show an academic elitism that they usually integrate in their academic duties in a way that is qualitatively downgrading. Consolidated beliefs and stereotypes from their work in conventional education, accompany their teaching at an open university. However, both the literature review and the research in the HOU (Papadimitriou, 2014) highlight that a different approach to learning with active participation, dialogue, and sharing within learning communities is necessary.

Tutors coming from conventional education refer to a "vague role" that they want to get to know more deeply. Typically they say "it was a bit chaotic/fuzzy and unclear what I had in my mind" about their work in the HOU and they also seek recognition regarding their special role, through the training process (Papadimitriou, 2014).

Research in the HOU highlights the lack of co-perception among teachers on different courses or between the modules in the same course. Since diversity of views is a structural element of scientific thinking, this pre-existing perception is not considered a negative element. However, the development of common principles is crucial for students in DE. The academic environment in DE is non-existent, either in physical or virtual space, even though the academic environment is an integral part of university activity, academic communication and scientific development.

Due to the specificity of the role and its diversity, the HOU needs to develop a policy of training and support for its teaching staff, including a theoretical study of and practical applications for the exercise of new teaching and counseling roles.

Open universities face challenges and they are called on to reexamine their role now that many traditional universities adopt DE programmes. Firstly, as A.Tait in an interview says, "an open university has always got to challenge the idea of what a 
university is" (Papadimitriou, Ioakimidou \& Spanaka et al, 2014:103). What is certain though is that open universities should also understand who their clients are, as M. Brown explains (Ioakimidou, 2016b), that is, people who might not ordinarily get a chance to enter HE and that's the contribution this kind of university makes to society and that's the narrative that should become known globally.

It seems that open and DE at least may offer:

- broad access to HE not just for the academic elite but for everybody;

- familiarization with the rationale of openness: OER, personal academic pathways and profiles, open libraries that offer access to journals and proceedings;

- educational material created to serve DE needs;

- use of technology and tools like social media, learning analytics;

- commitment to innovation and continuous improvement of quality;

- opening up to society and people's needs.

An educational institution alone may not bring about huge changes in society directly. However, it may contribute to the reduction of educational differences among the social classes, it may offer criteria to evaluate social circumstances and cultivate consciousness of social change towards fairer social constructions (Matsaggouras, 1991).

As far as the second research question regarding the challenges faced by the HOU nowadays is concerned, our research focuses on the following dimensions:

The Governing Committee at least in the last few years has shown the will to "wake up the giant" and to make critical changes in the university. One positive decision was the foundation of new locations by the end of 2017 in various cities like Athens and Thessaloniki that facilitate students all over the country by offering libraries and rooms to study, and hosting public events. The ability to establish new locations inside the country but also abroad was provided for from the time of the HOU's first operation and this was considered to be an innovation back in 1997 (Koustourakis, 2006:61). Regarding the educational material, good practices have been developed and harnessed, such as the critical reader, the DE expert in the design and development of the educational material, even though this legacy was put to one side, one hopes temporarily, as new programmes were started hastily in 2016.

After many years, new courses have been designed and operate which offer openings in new scientific fields and this is a positive step. The question of assessing the practices of design, development, applications and evaluation processes themselves in all courses, certainly remains.

There are still challenges such as the possibility that students should have to choose modules from various courses to create their own academic route/profile.

Twenty years after the foundation of the HOU, there are critical questions to be discussed like:

- Are there signs of maturation or formalism?

- Are there active mechanisms of continuous enhancement?

- Is there any policy related to the diffusion of the university's special open and DE culture and how could this be promoted?

The answers to these questions don't come easily. For example, there is no doubt that the HOU introduced in Greece in an emphatic way the notion that learning material appropriately designed for distance education "teaches" and that the tutors support the students' learning process. The educational material created twenty years ago was an innovation though there are no mechanisms to ensure its content and the delivery modes are updated today. Nor is there the necessary flexibility, for instance, to allow 
tutors to adjust their support and the students' work according to the learners' needs at different times. There are cases where the context is too "prefabricated" with no possibility for them to arrive at the desired end by following another path. However, notions like innovation, flexibility, continuous enhancement, and the practices that promote them, are fundamental in distance education and there is an urgent need to ensure that these are the fuel of everyday practice in the HOU as in every open university.

\section{Suggestions}

Defining the elements that compose open and DE, assessing them systematically in their implementation, in essence showing factors and conditions that affect products and processes, that designate ways and possibilities to enhance processes and transform the outcomes of reviews and research for strategic and policy decisions and actions that will be again assessed, is probably a harsh outline of a quality enhancement mechanism for open universities.

The following research and development suggestions could highlight some focus points (Hartofylaka, 2011; Papadimitriou, 2014; Ioakimidou, 2018):

- The development of a student support mechanism based on their needs in order to increase the chances of them completing their studies successfully. This could include foundation courses/ MOOCs.

- The development and assessment of educational material especially for open and DE as a result of specific methods of work and collaboration within the team of experts that interact and have various roles.

- The development and adaptation of OER that will support students' studies and the tutors' complex role. The use/reuse of OER for each cognitive field combined with proposals for personalized/collaborative learning will be a useful guide for tutors.

- The development of a repository with indicative learning scenarios aiming to support activities such as preparatory courses, evaluation of assignments, faceto-face meetings and dissertation support.

- The development of a mechanism that could accredit educational material, training or educational programmes and teaching/learning processes.

- The explicit, systematic use of the results and data from reviews and assessments in order to inform; enrich and enhance processes like the foundation of new programmes, the improvement of older modules/courses, the production of new educational material, and the tutors' professional development.

- The development and use of a quality assurance and enhancement mechanism that could embrace every aspect of the university's operation.

The article explores strengths, innovations and weaknesses in the HOU and focuses on aspects that threaten or inspire a quality culture of enhancement. The HOU case illustrates the achievements and the innovations brought to Greek HE and also its high impact in lifelong learning and adult education. The educational mobilization of a wider social class which was outside the educational process is also the great contribution of the HOU to the educational reform in the country and could be a transferable lesson to Open Universities worldwide. 


\section{References}

Apostolidou, A. (2011). Issues in the disciplinary constitution of open and distance learning: A review of the field's academic journals. Open Education: The Journal for Open and Distance Education and Educational Technology, Vol.7(1),36-53. Retrieved on 19 October 2017, from https://ejournals.epublishing.ekt.gr/index.php/openjournal/article/view/9767.

Hartofylaka, A.M. (2007). Towards a dynamic educational material in distance education. Open Education: The Journal for Open and Distance Education and Educational Technology, Vol.6,43-57. Athens: Propompos.

Hartofylaka, A.M. (2012). Quality assurance in the production of open and distance learning educational material: Setting standards for quality content. Hellenic Open University. Retrieved on 23 June, 2018 from https://www.didaktorika.gr/eadd/handle/10442/28372.

Holmberg, B. (1995). Theory and Practice of Distance Education. London: Routledge.

HOU, (nd). Hellenic Open University. Retrieved on 20 June, 2018 from https://www.eap.gr/el/.

Ioakimidou, V. (2018). The quality assurance in teaching and learning: implementations in the polymorphic distance education. Hellenic Open University. Retrieved on 26 July, 2018 from https://www.didaktorika.gr/eadd/handle/10442/44003.

Ioakimidou, V., \& Lionarakis, A. (2017). Quality assurance and quality enhancement in distance tertiary education. Trends and orientations. Open Education: The Journal for Open and Distance Education Technology, Vol. 13 (2), 124-139. Retrieved on 2 July, 2018 from https://ejournals.epublishing.ekt.gr/index.php/openjournal/article/view/15541.

Ioakimidou, V. (2016a). Interview with Diana Laurillard. Open Education: The Journal for Open and Distance Education Technology Vol.12(1),pp.127-135. Retrieved on 31 August, 2017 from https://ejournals.epublishing.ekt.gr/index.php/openjournal/article/view/10234.

Ioakimidou, V. (2016b) Interview with the professor Mark Brown. Open Education: The Journal for Open and Distance Education Technology Vol.12(1),pp.136-140. Retrieved on 31 August, 2017 from https://ejournals.epublishing.ekt.gr/index.php/openjournal/article/view/10233.

Jani, M. (1986). Issues on the sociology in Education. Athens: Grigoris.

Koustourakis, G. (2006). The effort of forming a context for the organization and the operation of the HOU: a sociological approach. In Author (Ed), Open and Distance Education-Elements of Theory and Practice (pp.42-77). Athens: Propompos.

Lionarakis, A., \& Papademetriou, D. (2003). The quality of the learning experience: a comparative study between open distance and conventional education. Turkish Online Journal of Distance Education (TOJDE), Vol.4(2). Retrieved on 19 September, 2017 from http://tojde.anadolu.edu.tr/makale_goster.php?id=87.

Lionarakis, A. (2006). Towards a theory of Open and Distance learning. Retrieved on 10 September, 2012

from http://class.eap.gr/QuickPlace/ekp65/PageLibraryC2256E84004300AE.nsf/h_47E6E21F3CD44 1CDC2256E8400469E08/ADF3738A12E6238DC2256E9B003B22CF/?OpenDocument.

Lionarakis, A. (2012). Teaching Material for the training of Tutor-counselors at the HOU. An introduction.

Manousou, E. (2008). Specifications for a pedagogical framework for the implementation of polymorphic, supplementary, environmental distance education for primary students of multigrade and rural schools in Greece. Hellenic Open University. Retrieved on 23 June, 2018 from https://www.didaktorika.gr/eadd/handle/10442/15961.

Matsaggouras, I. (1991). Teaching Methodology: theory and action of teaching. Athens.

Ossiannilsson, E., Williams, K., Camilleri, A. F., \& Brown, M. (2015). Quality models in online and open education around the globe: State of the art and recommendations. Oslo, International Council for Open and Distance Education. Retrieved on 21 September, 2017 from https://www.google.gr/search?q=Quality+models+in+online+and+open+education\&ie=utf8\&oe=utf-8\&client=firefox-b\&gfe $r d=c r \& d c r=0 \&$ ei=IhrEWaGKGoaBX6T-mKAN.

Pacey, L. \& Keough, E. (2003). Public Policy, Institutional Structures, and Strategic Implementation. $\Sigma \tau$ o Moore, G. M. \& Anderson, W. G. (Ed.) Handbook of Distance Education. London: Lawrence Erlbaum Associates. Retrieved on 2 November, 2012, from http://www.uady.mx/ contadur/seccip/articulos/libros_online/educacion/LawrenceErlbaum2003HandbookOfDistanceEducation.pd f.

Panagiotakopulos, C. \& Author (2001). The profile of candidate students of the HOU at the first time of its operation (1999-2000). In Author(Ed.) Open Education - Views and Reflections on Open and Distance Learning (pp.33-77). Athens: Propompos. 
Papadimitriou, S., Ioakimidou, V., \& Spanaka, A. (2014). Interview with Alan Tait. Open Education: The Journal for Open and Distance Education Technology Vol. 10(1), pp.101-106). Retrieved $\begin{array}{lllll}\text { on } & 31 & \text { August, } & 2017 & \text { from }\end{array}$ https://ejournals.epublishing.ekt.gr/index.php/openjournal/article/view/9839.

Papadimitriou, S. (2014). The role of tutor-counselor and the development of his supporting mechanism in a collaborative learning environment in distance education. Hellenic Open $\begin{array}{llllll}\text { University. } & \text { Retrieved } & 2018 & \text { June, } & \text { from }\end{array}$ https://www.didaktorika.gr/eadd/handle/10442/38040.

Passias, G. (2012). The "quality", the "Europe of indicators" and the policies of numbers. In Trilianos, Koutromanos \& Alexopoulos(Eds). Pan-Hellenic Conference with International Participation. The Quality in Education: trends and prospective, 11-13 May 2012 (Vol.B, pp.41-51). National University of Athens.

Rowntree, D. (1994). Preparing Materials for Open, Distance and Flexible Learning: An Action Guide for Teachers and Trainers. London: Kogan Page.

Shah, M., Nair, C.S. (2014). Turning the ship around. Rethinking strategy development and implementation in universities. Quality Assurance in Education, Vol.22(2),145-157. Retrieved $\begin{array}{lllll}\text { on } & 6 & \text { September, } & 2017 & \text { from }\end{array}$ http://www.emeraldinsight.com.proxy.eap.gr/doi/pdfplus/10.1108/QAE-03-2012-0016.

Siakas, S. (2011). Contribution of animation and film narrative in the creation of multimedia learning for teaching / learning aims (unpublished PhD thesis). Hellenic Open University. Retrieved on 23 June, 2018 from https://www.didaktorika.gr/eadd/handle/10442/30153.

Steinhardt, I., Schneijderberg, C., Gotze, N., Baumann, J., \& Krucken, G. (2017). Mapping the quality assurance of teaching and learning in higher education: the emergence of a specialty? Higher Education, Vol.74(2),221-237. Retrieved on 21 August, 2017 from https://link-springercom.proxy.eap.gr/content/pdf/10.1007\%2Fs10734-016-0045-5.pdf.

Tait, A. (2015). Student success in open, distance and e-learning. Oslo: International Council for Open and Distance Education-ICDE. Retrieved on 17 October, 2017 from https://eadtu.eu/news/20general-news/257-student-success-in-open-distance-and-e-learning.

The Commonwealth of Learning-CoL, (2003). Tutoring In Open And Distance Learning: A Handbook For Tutors, ISBN 1-895369-87-8, Published by: The Commonwealth of Learning Vancouver, CANADA. Retrieved on May 15, 2013 from http://www.col.org.

Woodhouse, D. (1998). Quality Assurance in Higher Education: the next 25 years. Quality in Higher Education, Vol.4(3), 257-273. Retrieved on 2 September, 2010 from http://www-tandfonlinecom.proxy.eap.gr/doi/pdf/10.1080/1353832980040306. 